\title{
Reviews
}

\section{THE HAEMADSORPTION AT AFRICAN SWINE FEVER (review)}

\section{A.D. SEREDA ${ }^{1}$, A.R. IMATDINOV', V.V. MAKAROV ${ }^{2}$}

\author{
${ }^{1}$ All-Russian Institute of Veterinary Virology and Microbiology, Federal Agency of Scientific Organizations, 1, ul. \\ Akademika Bakuleva, pos. Vol'ginskii, Petushinskii Region, Vladimir Province, 601125 Russia, e-mail sereda- \\ 56@mail.ru; \\ ${ }^{2}$ Peoples' Friendship University of Russia, Agro-Technological Institute, 8/2, ul. Miklukho-Maklaya, Moscow, 117198 \\ Russia, e-mailvvm-39@mail.ru \\ Acknowledgements: \\ Supported by Russian Science Foundation (the research project «Design of African swine fever virus candidate \\ vaccine based on chimeric viruses», contract No 16-16-00090) \\ Received August 29, 2016
}

\section{Abstract}

The capability of causing haemadsorption at African swine fever (ASF) virus (ASFV) reproduction in swine bone marrow cell cultures, leukocytes or continuous cells in the presence of swine erythrocytes is characteristic of the majority of the virus isolates (W.A. Malmquist, D. Hay, 1960). This trait is used for ASF diagnosis based on autohaemadsorption in porcine blood, the virus titration in cell culture, and selection of its attenuated variants in vitro (A.D. Sereda et al., 2014). The haemadsorption inhibition assay (HIA) in tandem with the bioassay using the disease-resistant pigs is applied for seroimmunotype-based classification of ASFV isolates (N.I. Mitin et al., 1985). The heterogeneity of an ASFV population for quantitative haemadsorption characteristic (like «dense», «moderate» or «loose») is a phenotypic trait of ASFV isolates, strains and/or variants (V. Makarov et al., 2016). Also, the proportion of the circumference of red blood cells as observed at their contact with infected macrophages serves as another quantifiable feature of haemadsorption. Some quantitative differences in HIA activity levels of swine blood sera are determined in the assays carried out using virulent reference variants and their attenuated derivatives, and the obtained results require some interpretation. The loss of ability to induce haemadsorption is not critical for ASFV reproduction and often accompanied by a decrease in the pathogen virulence levels. Hence, as a rule, attenuated ASFV variants are prepared through a selection by limiting dilution from populations of virulent isolates of the virus clones that are characterized by a reduced potential to induce haemadsorption (D.V. Kolbasov et al., 2014). In the course of the virus reproduction, haemadsorption precedes the exocytosis. Virions do not play a significant role in the mechanism of haemadsorption, nevertheless, their interaction with erythrocyte membranes promotes the virus dissemination throughout the swine organism and more effective introduction into the gut cells of ticks (L.K. Dixon et al., 2004). ASFV haemadsorbing potentiality is determined by highly glycosylated transmembrane protein CD2v (J.M. Rodríguez et al., 1993). Probably, nonhaemadsorbing avirulent isolates emerge as a result of some shift of the open reading frames for EP402R and EP153R encoding the CD2v and lectin-like proteins, respectively (D.A. Chapman et al., 2008). An assumption is made that the haemadsorption phenomenon is due to an interaction between carbohydrate residues of glycoproteins of ASFV oligosaccharides and lectin-like receptors of swine red blood cells.

Keywords: African swine fever, haemadsorption, non-haemadsorbing isolates

The pathogen of African swine fever is a large DNA-containing virus of Asfarviridae family [1]. Its virulent isolates may cause the disease in domestic swine (Sus scrofa domesticus) and wild boars (Sus scrofa). In Africa, ASF is supported in the transmission cycle between its natural hosts, wart hogs (Phacochoerus spp.) and bushpigs (Potomochorus porcus), and its transmitters - soft ticks Ornithodoros [2]. The disease is contagious, and the virus is well adapted to its hosts inducing a sub-clinical chronic or unapparent form of infection.

The interest in haemadsorption in the course of the ASF virus (ASFV) reproduction is driven by several factors. So far, different aspects remained un- 
clear, particularly, what molecular mechanisms underline ASFV heterogeneity by haemadsorption, why some isolates do not have this feature and how the haemadsorption capacity is related to other phenotypic characteristics of isolates and laboratory variants. In the veterinary practice, haemadsorption is used for ASFV titration (as in most cases, the obtained results coincide with the titration data by the cytopathic effect), in the selection of attenuated variants, and lifetime disease diagnosis by the autohaemadsorption of blood leukocytes in the infected swine. The haemadsorption inhibition test (HIT) is used, together with the bioassay study of the disease-resistant swine, to classify the ASFV isolates by their immunoserotypes [3-5].

Haemadsorption phenomenon. It is well known that the cell cultures, which are infected with the orthomyxo-, paramyxo-, toga-, rhabdo-, and poxviruses capable of shedding viral progeny via budding, can absorb erythrocytes $[6,7]$. Haemadsorption is caused by the inclusion of synthesized virus proteins having an affinity to erythrocytes into the cell membrane. In a number of cases it has common mechanisms with haemagglutination and is observed at early virus reproduction cycle until the development of the cytopathic effect or in its absence or its weak intensity.

Haemadsorption in the course of ASFV reproduction was first identified and described by W.A. Malmquist and D. Hay [3]. By showing that the sera of the swine that had ASF restricted haemadsorption but did not neutralize the cytopathic effect and did not affect the virus reproduction, they assumed that the antigen responsible for haemadsorption is not related to virions. S.S Brees and W.R. Hess [8] ascertained that the integrity of the plasmalemma of the infected cells is an essential condition for haemadsorption in the course of ASFV reproduction. Electronic microscopy revealed two key ways of erythrocytes binding with the cell membrane at haemadsorption, i.e. by attaching to cell filaments protruding out of the plasmalemma, and directly to the membrane of the infected cell [8]. The membrane of the infected cell acquires the capacity to absorb erythrocytes before the virions start migration from the cytoplasmic matrices where they mature. In other words, the virus specific modulation of the cell membrane not just precedes the virus exocytosis, but is chronologically ahead of it, and these stages are not synchronized [9, 10].

The majority of researchers think that the virus particles are not necessarily located at the site of contact between the erythrocytes and the cell [11, 12]. Visually, at $\times 400$ magnification erythrocytes are seen on the macrophage arranged either in one layer or in several layers. Their number per haemadsorbing cell varies from to 80 or more cells. It was shown [13] that the multi-layer appearance in case of the so-called dense haemadsorption results from the changes in the form of erythrocytes and the cytoplasm protuberances of the infected macrophage, contacting erythrocyte, that are located at a significant distance from the main part of cell. The absence of hemagglutination in the course of ASF also evidences that virions do not play any role in the haemadsorption phenomenon. When fluorescent antibodies and the monoclonal antibodies to ASFV-specific $13 \mathrm{kDa}$ and $73 \mathrm{kDa}$ polypeptides were used in the study of interaction between virions and erythrocytes in 30 pigs infected with 17 ASFV isolates, the viral antibodies were in vitro and in vivo observed on the surface of swine erythrocytes [14]. By a transmission microscopy, virions were identified in the invaginations of membranes on the surface of erythrocytes [14]. The virus binds to erythrocytes as soon as they interact with the infected cells. Virions attach to the surface of the erythrocyte cell membrane, but remain in the membrane invaginations without penetrating to the cytoplasm. This mechanism may preserve the virus in blood. The attachment of virions to erythrocytes seems to 
contribute significantly to the ASFV penetrating through the intestinal walls in ticks due to the erythrocyte phagocytosis by hemocoel cells [15]. It is noted that haemadsorption does not occur in all cells with virus replication or the presence of virus particles [16].

Quantitative characteristics of haemadsorption. The number of attached erythrocytes. Haemadsorption is considered as the ability of infected cells to bind the erythrocytes contained in a cell culture, keeping them when the culture is washed. Comparative analysis of haemadsorption phenomenon showed that ASFV isolates, strains and variants significantly differed in the quantitative haemadsorption parameters and the population structure correlating to the virulence. The number of erythrocytes attached to a cell in swine marrow cell (SMC) culture varied significantly between attenuated strain FK-32/135 and the virulent F-32 and Kiravira-67 strains, and the distribution by this parameter was close to normal. The arithmetic average number of erythrocytes per haemadsorbing cell in the variation series of the studied strains were not the same, being low for FK-32/135 (18.52 \pm 0.36$)$, and higher for France-32 and Kiravira-67 (29.32 \pm 0.71 and $34.49 \pm 0.89$, respectively) [17]. Heterogeneity and specificity on qualitative haemadsorption parameters are typical of each strain population, e.g. there was a simultaneous occurrence of dense (41-80 erythrocytes per cell), intermediary (21-40 erythrocytes) and loose (1-20 erythrocytes) haemadsorption in a field of view, but in various proportions (Fig.).
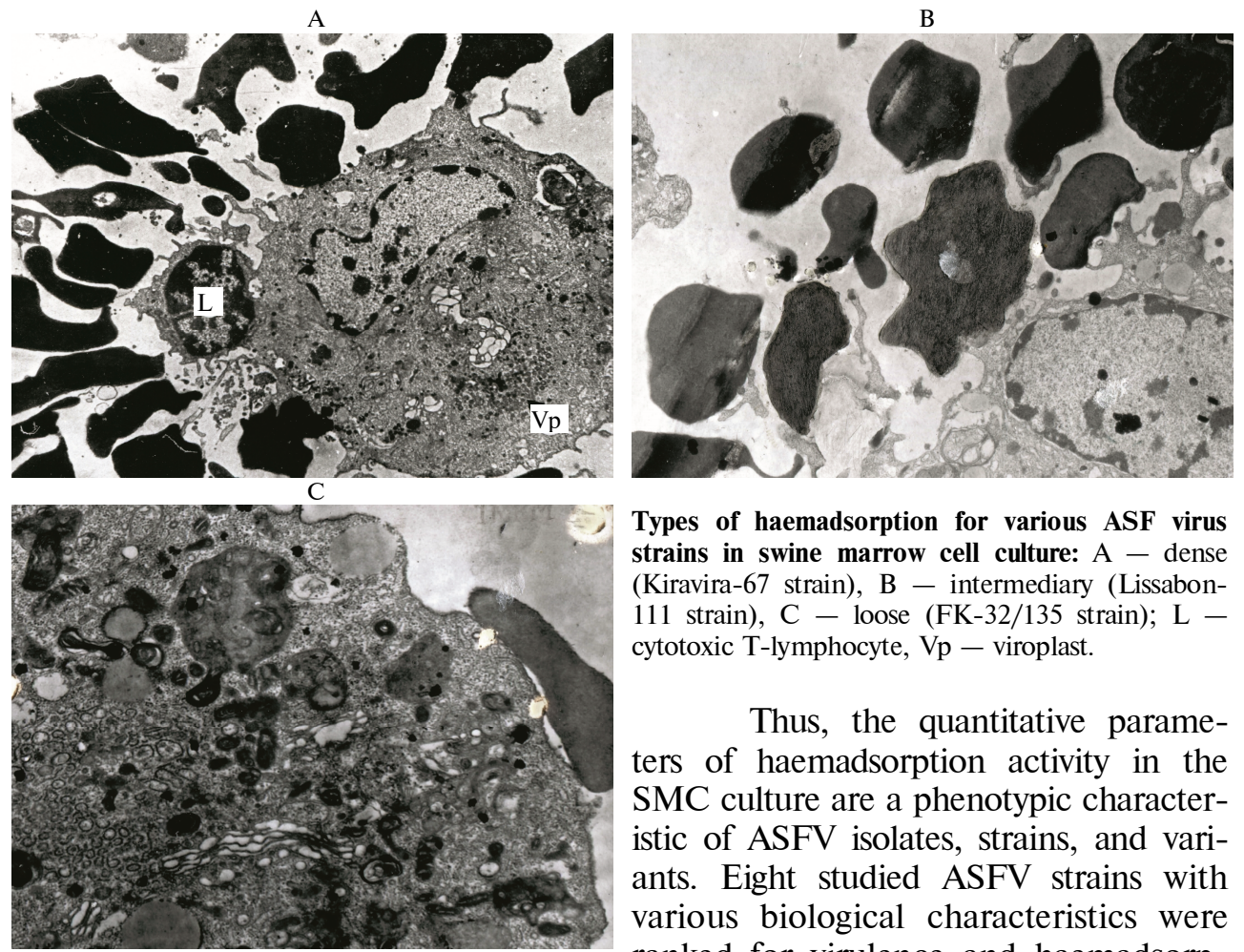

Types of haemadsorption for various ASF virus strains in swine marrow cell culture: A - dense (Kiravira-67 strain), B - intermediary (Lissabon111 strain), C - loose (FK-32/135 strain); L cytotoxic T-lymphocyte, $\mathrm{Vp}$ - viroplast.

Thus, the quantitative parameters of haemadsorption activity in the SMC culture are a phenotypic characteristic of ASFV isolates, strains, and variants. Eight studied ASFV strains with various biological characteristics were ranked for virulence and haemadsorption activity, that was indicative of genetic control of haemadsorption antigen

expression $[17,18]$. In the attenuated (avirulent) ASFV variants there were only the subpopulations with loose and intermediary haemadsorption, while in the virulent strains, on the contrary, the subpopulations with intermediary and dense types were observed. These findings allow to assume that antigen modulation of infected mononuclear macrophages is more typical of the avirulent variants [19]. 
Differences between the strains in the contact circumferencee ratio of erythrocyte at interaction with a macrophage. For the avirulent attenuated strain FK$32 / 135$ with loose one-layer haemadsorption, the ratio of erythrocyte circumference contacting the plasmalemma of the infected macrophages was $34.2 \pm 7.3 \%$, while shorter intermembrane contacts, $7.8 \pm 3.1 \%$ for France-32 and $11.2 \pm 6.4 \%$ for Kiravira-67, are typical of virulent strains with dense haemadsorption. These results may also be interpreted as the evidence for antigen modulation of the membrane of the infected monocytes (macrophages), which is more typical of avirulent variants, and as an indication of the high affinity of haemadsorbing protein in virulent variants.

The differences in the activity of serums in HIT with virulent and attenuated ASFV strains. A study of the antibodies involved in HIT when testing blood serum of swine, which survived after acute, ASF resulted in interesting findings. In the study, three specific antisera of serotype I were tested with the virulent strain Lisbon-57 and its attenuated derivatives (L-50, LK-111, and LK-200); five antisera of serotype II were tested with virulent strains (Yamba-20, Kongo-49) and attenuated strain KK-202 derived from strain Kongo-49; five antisera of serotype III were tested with virulent strain Mozambique-78 and its attenuated derivatives MK-200 and MK-250; and six antisera of serotype IV were tested with strain France-32 and its attenuated derivative FK-32/135, strain Portuguese-60 and its attenuated variant P60/81, and strain Brazil-80. The titers of antiserf in HIT with virulent strains were 1.7-2.8 $\log _{2}$ lower than with homological attenuated strains. More differences were observed for attenuated strain FK-32/135 inducing loose haemadsorption, hence France-32 had 29.5-fold lower antiserum titers in HIT compared to FK-32/135 [20]. In other words, substantially fewer amounts of antibodies are required for inhibition at loose haemadsorption than at dense one.

The hypothesis according to which in infected SMC culture or swine leukocyte (SL) culture the lysis of target cells, due to antibody-dependent cellular cytotoxicity (ADCC), can fully or partially compete with the development of haemadsorption and imitate its inhibition was verified experimentally [21). However, in five blood sera the antibody titers in HIT with the variant of FK-135 adapted to cell line coincided both in primary FK-135-infected SMC culture with active ADCC mechanism, and in swine embryo kidney cell line, the PPK$66 \mathrm{~b}$, which contained no ADCC effectors. This is the evidence that ADCC and HIT occur simultaneously and independently of each other [21].

ASFV reproduction, as influenced by the glycosilation inhibitors. Inhibition analysis is a very informative tool in studying biosynthesis and morphogenesis of viruses, including processing of their structural and nonstructural proteins in an infected cell. Non-cytocide concentrations of inhibitors are determined, in particular, based on the optical and electron microscopy data [22]. To study the role of glycosilation in the ASFV reproduction, its strains, isolates and variants were grouped according to seroimmunotype specificity, common origin and contrasting key biological features [23]. Each group of the isolates included a reference strain of seroimmunotypes I-IV and, as a rule, attenuated laboratory variants derived from the corresponding strains. Reference strains were high virulent and able to induce dense haemadsorption during the reproduction in the SMC culture. Their attenuated variants were either low virulent or avirulent, and haemadsorption during the reproduction in the SMC culture was less dense (even loose). Furthermore, non-haemadsorbing isolates were studied.

It is known that tunicamicin blocks the formation of dolicol-PP-acetyl-Dglycosamine (the first stage in the dolicol-dependent protein glycosylation) [24]. The effect of introducing tuncamicin into the infected SMC culture differed de- 
pending on the phenotype of the investigated strains, isolates and variants of the ASF virus. Titers of the reference strains Lissabon-57 (seroimmunotype I), Kongo-49 (seroimmunotype II), and France-32 (seroimmunotype IV) were more reduced than in the laboratory attenuated strains and variants LK-111 and LC (I), FK-32/135, FNG (IV), and non-haemadsorbing isolate Petit-Engre (II). Within non-cytocide concentrations of tuncamicin $\left(0.5-1.0 \mu \mathrm{g} / \mathrm{cm}^{3}\right)$ the difference in the accumulated infectious progeny between the virulent and attenuated ASFV strains of seroimmunotype I, II, and IV was 10-fold (about $1.0 \mathrm{lg} \mathrm{CPE}_{50}$ ). And only the strain Mozambique-78 and its attenuated variant MK-200 (seroimmunotype III) had no such differences. The ionophore monensin equally suppressed the reproduction of all studied virus strains and variants [23].

Electron microscopy showed that tunicamicin, the glycosylation inhibitor, did not affect the structure of virus matrices and the timing of virion budding, however in the presence of tunicamicin budding virions showed a notable association with the vacuole membranes of the Golgi apparatus. At tunicamicin concentration of $0.5 \mu \mathrm{g} / \mathrm{cm}^{3}$, the yield of the ASFV strain France32 in SMC culture reduced by $1.2 \pm 0.2 \mathrm{lg} \mathrm{HAU} \mathrm{H}_{50} / \mathrm{cm}^{3}$ as compared to control (without inhibitor). In the presence of tunicamicin, the number of virions associated with the membranes of the Golgi apparatus and their ratio was 84 (50\%), without the inhibitor $-43(13 \%)$, the number of virions associated with plasmalemma was 181 (50\%), without the inhibitor - $281(87 \%)$ [23].

Consequently, when glycosylation is inhibited, the assembly of capsids is not violated and their number does not decrease, but because of the infringed transportation of glycoproteins to the plasma membrane the virion budding into the Golgi vacuole apparatus increases leading to a reduced yield of the extracellular virus. Thus, the production of infectious progeny in haemadsorbing ASFV strains and variants depends on glycosylation.

Effect of monosaccharides, exo- and endoglycosidases on ASFV haemadsorbtion. No haemadsorbtion is observed in swine marrow Acells (adhesive cells) treated with tuncamicin and monensin inhibitors and then infected with haemadsorbing ASFV strains [23]. This allowed us to assume that haemadsorption results from an interaction between carbohydrate components of ASFV glycoproteins and the lectin-like receptors of erythrocytes. For elucidation, we have studied whether the treatment with exo- and endoglycosidases, and the presence of various monosaccharides in the culture medium could influence haemadsorption in ASFV-infected swine marrow A-cells (Table) [23].

Haemadsorption in swine marrow A-cells infected with African swine fever virus (strain France-32), as influenced by agents affecting carbohydrate component of the viral glycoproteins [23]

\begin{tabular}{|c|c|c|c|}
\hline Agent & In 1 hour & In 2 hours & In 3 hours \\
\hline \multicolumn{4}{|c|}{ Effect of $x$ o- and endoglycosidases } \\
\hline \multicolumn{4}{|l|}{ Enzymes, units $/ \mathrm{cm}^{3}$ : } \\
\hline neuraminidase, 10 & + & + & + \\
\hline$\beta$-galactosidase, 150 & - & + & + \\
\hline$\beta$-glycosidse, $50-100$ & + & + & + \\
\hline$\alpha$-mannosidase, 8.5 & - & - & - \\
\hline endoglycosidase $\mathrm{D}, 0.1$ & + & + & + \\
\hline endoglycosidase $\mathrm{F}, 0.1$ & - & - & - \\
\hline \multicolumn{4}{|c|}{ Effect of monosaccharides } \\
\hline \multirow{2}{*}{\multicolumn{4}{|c|}{$\begin{array}{l}\text { Monosaccharides, \%: } \\
\text { D-glucose }\end{array}$}} \\
\hline & & & \\
\hline 1.25 & + & + & + \\
\hline 2.50 & + & + & + \\
\hline 5.00 & + & + & + \\
\hline \multicolumn{4}{|l|}{ L-fructose } \\
\hline 1.25 & + & + & + \\
\hline 2.50 & + & + & + \\
\hline 5.00 & + & + & + \\
\hline
\end{tabular}



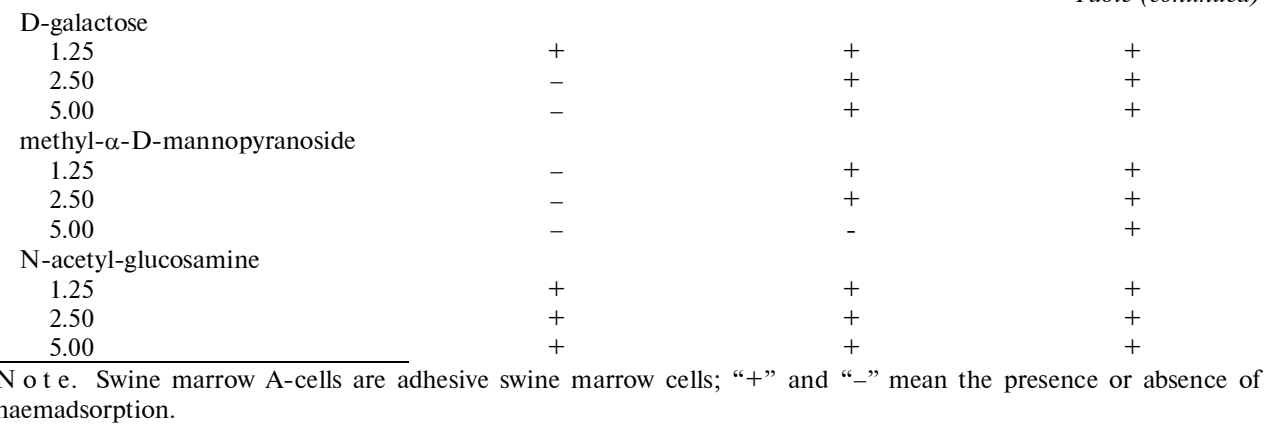

N o t e. Swine martion.
haemadsorption.

Since exoglycosidases split out only monosaccharide residues, the nonregenerated ends of ASFV oligosaccharides in haemadsorbing protein evidently contain $\alpha$-mannose. It is confirmed by haemadsorption inhibition with methyl- $\alpha-D-$ mannopyranoside, and by its sensitivity to endoglycosidase $\mathrm{F}$, specific to highmannose glycans [25]. The obtained results evidence that high-mannose oligosaccharides of the ASFV glycoproteins are involved into haemadsorption.

Non-haemadsorbing ASFV isolates, strains, and variants. In Africa, non-haemadsorbing ASFV variants were isolated from chronically infected wild (wart hogs, bushpigs) and domestic, including indigenous, pigs, as well as from ticks Ornitodoros moubata [26-32]. In the course of passaging on domestic swine or in primary SMC culture some isolates recovered their haemadsorbing activity, while others did not [33]. From 1972 to 1985, 79 ASFV isolates were found in the survey of over 7,000 pigs of European and domestic breeds in the People's Republic of the Congo. It was shown that under natural epizooties and experimental selection the cultural and pathogenic characteristics of ASFV were substantially modified, i.e. ASFV could lose haemadsorbing capacity or reduce virulence up to its complete loss. Among local animals, the ASFV often circulated in a non-haemadsorbing form causing no clinical signs and creating a positive immune profile [34, 35].

In Europe, non-haemadsorbing ASFV strains are generally isolated from chronically ill domestic swine and ticks Ornitodoros erraticus. For example, 206 non-haemadsorbing isolates were collected in Spain from 1965 to 1974 [26]. In Portugal, 10 ASFV isolates derived from the ticks Ornitodoros erraticus, collected from 1988 to 1993, six of which were haemadsorbing and pathogenic, and four were non-haemadsorbing and non-pathogenic [27]. With passages on intact domestic swine, the ASFV genome is little subject to modification: its similarity was shown after 20 passages on swine, and after 17-100 passages in swine alveolar macrophage culture $[36,37]$. At the same time, it was reported that the virulent and (or) haemadsorbing capacity were lost after long passaging of haemadsorbing isolates in primary cell cultures and in cell line cultures [38, 39].

It is considered that the loss of haemadsorbing phenotype does not affect the pathogenicity of the ASFV isolates. Non-haemadsorbing isolates sampled from swine in the centers of disease in South Africa and in Madagascar caused death in 80-90\% of animals [40]. However, many researchers pointed to the low virulence and protective features of non-haemadsorbing natural isolates and the obtained laboratory variants $[11,28,41,42]$. By direct and selective passages in the swine marrow cell culture from highly reactogenic strain Katanga-105 (seroimmunotype I), causing death in $87 \%$ of domestic pigs, after 44 direct passages in the swine marrow cells, a non-haemadsorbing variant $\mathrm{KC}-149$ was obtained that became avirulent for the swine. It kept its features up to passage 190, did 
not reverse after three passages on the swine, and protected the animals from death after subsequent intramuscular infection with the virulent reference strain Lissabon-57, seroimmunotype I, at dosage of $10^{4} \mathrm{HAU}_{50}[43,44]$.

When studying the effect of $\gamma$-radiation on the ASFV, we obtained unexpected results. The preparations of haemadsorbing and non-haemadsorbing ASFV isolates, strains and variants (non-concentrated and concentrated) that lost their infectivity after being exposed to radiation of $25 \mathrm{kGr}$ ( $\gamma$-radiated preparations, $\gamma$-RP) induced haemadsorption when being introduced into the swine marrow cell culture. In sub-passages ( 3 to 8 ), this effect was not reproduced and the infectious ASFV was not isolated in the tested samples. By the character of erythrocytes location, haemadsorption caused by $\gamma$-RP practically did not differ from the loose one that was observed in the SMC culture infected, for instance, with attenuated strain FK-32/135. Based on data on i) haemadsorption development, ii) identification of virus-specific antigens in swine marrow A-cells infected with $\gamma$-RP by immunofluorescence and immunoblotting, and iii) the effect of inhibitors of RNA synthesis and glycolization, it was proved that in this case haemadsorption was caused by de novo synthesis of virus-specific proteins encoded by intact regions of the ASFV genome. We demonstrated the serologic type specificity of haemadsorption induced by $\gamma$-RP of non-haemadsorbing ASFV isolates, which made it possible their serotyping in vitro [45].

Proteins involved in haemadsorption in case of ASFV. I.D. Vigario et. al [46] suggested that the existence of non-haemadsorbing ASFV isolates and strains is related to the deficiency of the protein, responsible for their haemadsorption, at reproduction. Later it was ascertained that the haemadsorbing features of the ASFV are determined by its transmembrane protein that is similar to the protein of the CD2 host cells [47, 48]. The virus-specific CD2-like protein was designated as $\mathrm{CD} 2 \mathrm{v}$. Its $\mathrm{mRNA}$ is transcribed due to the open reading frame (ORF) in gene EP402R [49]. The extracellular domain CD2v is similar to that of the host CD2 binding protein and contains two Ig-like domains and 15 potential sites for $\mathrm{N}$-glycolization unlike 3-4 in CD2 [48, 50, 51]. The molecular weight of the full-size glycosylated $\mathrm{CD} 2 \mathrm{v}$ in the isolate Malawi LIL20/1 is $105-110 \mathrm{kDa}$ [52]. In the absence of gene encoding CD2v protein in the virulent ASFV genome impeded the viremia and dissemination of the virus in swine body, but did not reduce the death from the virus. In the blood of an infected swine, the expression of $\mathrm{CD} 2 \mathrm{v}$ protein of extracellular virus particles correlated to the activity of binding erythrocyte. Therefore, according to the authors, the loss of haemadsorbing phenotype may be the factor of low or sporadic viremia as observed in case of infections caused by non-haemadsorbing isolates. However, other features of $\mathrm{CD} 2 \mathrm{v}$ may also be the reason for reduced virus reproduction in the host's organism. For expamle, CD2v expression suppresses lymphocyte proliferation in response to mitogens in vitro, which indicates that CD2v plays an important role in ASFV escaping from the host's immune system $[53,54]$. It is considered that the interaction between CD2v and its ligand on erythrocytes is stabilized as a result of the expression of virus-specific lectin-like protein of C-type coded by ORF EP153R, as the deletion of EP153R leads to a decreased haemadsorption around the ASFV infected cells [55-57]. It was shown that EP153R protein inhibits apoptosis and decreases expression of antigen of the main histocompatibility complex class I in swine SLA I [58, 59]. It was ascertained that the reading frames EP153R and EP402R are shifted in the genome of non-haemadsorbing avirulent isolates OURT88/3 and NHV, which ultimately causes this phenotype [60-62]. Interestingly, the recovery of the haemadsorbing phenotype in the strain NHV led to an increased virus reproduction in ticks, but not in swine [63]. 
In the swine marrow A-cells infected with haemadsorbing ASFV strains and marked with ${ }^{3} \mathrm{H}$-glycosamine a serotype specific $110-140 \mathrm{kDa}$ glycoprotein was identified by radio immunoprecipitation assay with HIT-active homological antisera [64]. The authors considered this glycoprotein to be involved in haemadsorption due to the fact that this glycoprotein could not be identified when the swine marrow A-cells were infected with non-haemadsorbing isolates and strains, or when using in immunoprecipitation the swine sera non-active in HIT, in particular, those obtained after the animals were infected with attenuated ASFV strains [64].

So, haemadsorption at African swine fever (ASF) has quantiative characteristics. The loss of capability to induce haemadsorption is followed by a reduced virulence. The ability of binding membrane of erythrocytes absorbed on macrophages helps the virus to disseminate in swine organism and contributes to more efficient penetration to the intestinal cells in ticks. The haemadsorbing features of the ASF virus are determined by transmembrane high glycosylated protein CD2v. Based on the inhibition analysis, it can be assumed that haemadsorption is caused by the interaction between the oligosaccharides of ASF virus glycoproteins and the lectin-like receptor of swine erythrocytes.

\section{REFERENCES}

1. Dixon L.K., Costa J.V., Escribano J.M., Rock D.L., Vinuela E., Wi1k in s o n P.J. Family Asfarviridae. In: Virus taxonomy: seventh report of the International Committee on Taxonomy of Viruses. M.H.V.V. Regenmortel, C.M. Fauquet, D.H.L. Bishop, E.B. Carstens, M.K. Estes, S.M. Lemon, J. Maniloff, M.A. Mayo, D.J. McGeoch, C.R. Pringle, R.B. Wickner (eds.). Academic Press, San Diego, CA, 2000: 159-165.

2. Sanchez-Vizca 1 no J.M., Mur L., Mart 1 nez-Lopez B. African swine fever: An epidemiological update. Transbound. Emerg. Dis., 2012, 59(1): 27-35 (doi: 10.1111/j.18651682.2011.01293).

3. M a l m qu is t W.A., H a y D. Hemadsorbtion and cytophatic effect produced by African swine fever virus in swine bone marrow and buffy coat culture. Am. J. Vet. Res., 1960, 21: 104-108.

4. Malogolovkin A., Burmakina G., Titov I., Sereda A., Gogin A., Baryshnikova E., Kolbasov D. Comparative analysis of African swine fever virus genotypes and serogroups. Emerg. Infect. Dis., 2015, 21(2): 312-315 (doi: 10.3201/eid2102.140649).

5. Kolb a s ov D.V., B a ly she v V.M., S e red a A.D. Veterinariya, 2014, 8: 3-8 (in Russ.).

6. Uhlendorff J., Matrosovich T., Klenk H.D., Matrosovich M. Functional significance of the hemadsorption activity of influenza virus neuraminidase and its alteration in pandemic viruses. Arch. Virol., 2009, 154: $945-957$ (doi: 10.1007/s00705-009-0393-x).

7. Saburi Y., Okuda K., Takhashi T. Electron microscopic study of gemadsorbtion on vaccinia virus infected cells. Microbiol. Immunol., 1977, 21(10): 593-600.

8. B reese S.S., Hess W.R. Electron microscopy of African swine fever virus hemadsorbtion. J. Bacteriol., 1966, 92(1): 272-274.

9. Makarov V., N e d o s e k o v V., S e re d a A., M a t vi e n k o N. Immunological conception of African swine fever. Zoology and Ecology, 2016, 26(3): 236-243 (doi: 10.1080/21658005.2016.1182822).

10. M a k a r o v V.V. Afrikanskaya chuma svinei [African swine fever]. Moscow, 2011 (in Russ.).

11. Coggins L. Segregation of a non-hemadsorbing African swine fever virus in tissue culture. The Cornell Veterinarian, 1968, 58(1): 12-20.

12. Coggi ns L. African swine fever virus. Pathogenesis. Prog. Med. Virol., 1974, 18: 48-65.

13. M a la k hov a M.S. Vzaimodeistvie virusa ACHS s immunokompetentnymi kletkami svin'i. Kandidatskaya dissertatsiya [ASF virus interaction with immune cells in pigs. PhD Thesis]. Pokrov, 1987 (in Russ.)

14. Qu i n t e ro J.C., We s l e y R.D., Why a rd T.C., G regg D., M e bu s C.A. In vitro and in vivo association of African swine fever virus with swine erythrocytes. Am. J. Vet. Res., 1986, 47(5): 1125-1131.

15. Rowlands R.J., Duarte M.M., Boinas F., Hutchings G., Dixon L.K. The $\mathrm{CD} 2 \mathrm{v}$ protein enhances African swine fever virus replication in the tick vector, Ornithodoros erraticus. Virology, 2009, 393: 319-328 (doi: 10.1016/j.virol.2009.07.040).

16. Sierraj M.A., Gomez-Villamanld C., Rasco O., Fernandeez A., Jover A. In vivo study of hemadsorption in African swine fever virus infected cells. Vet. Pathol., 1991, 28: $178-181$. 
17. Makarov V.V., V is h y a k ov I.F., V la s ov N.A., S e rova A.M. Voprosy virusologii, 1991, 4: 321-324 (in Russ.).

18. M a k a rov V.V., Suk harev O.I., T s ve t nova I.V. Veterinarnaya praktika, 2013, 60(1): 6-16 (in Russ.).

19. M a k a r o v V.V. Veterinarnaya praktika, 2013, 62(3): 7-22 (in Russ.).

20. Miti n N.I., Shevchenko A.A., B a lys ev V.M., Elis ova S.N. Differentsiatsiya virulentnykh i attenuirovannykh shtammov virusa ACHS v RZGA. Tezisy nauchnoi konferentsii VNIIVViM, posvyashchennoi 40-letiyu Velikoi Pobedy «Voprosy veterinarnoi virusologii, mikrobiologii $i$ epizootologii» [Proc. Conf. «Veterinary virology, microbiology and epizootology»]. Pokrov, 1985: 39-41 (in Russ.).

21. Shubina N.G., Kolontsov A.A., Malakhova M.S., Makarov V.V. Byulleten' eksperimental'noi biologii i meditsiny, 1996, 122(10): 418-424 (in Russ.).

22. Š e re š M., Cholujová D., Bube nčíkova T., B rei e r A., Sulová Z. Tunicamycin depresses P-glycoprotein glycosylation without an effect on its membrane localization and drug efflux activity in L1210 cells. Int. J. Mol. Sci., 2011, 12(11): 7772-7784 (doi: 10.3390/ijms12117772).

23. Makarov V.V., S e reda A.D., Pirya A.A., Malakhova M.S. Voprosy virusologii, 1992, 5-6: 267-270 (in Russ.).

24. Reszka N., Krol E., P at e 1 A.H., S zew c z y k B. Effect of tunicamycin on the biogenesis of hepatitis C virus glycoproteins. Acta biochimika Polonica, 2010, 57(4): 541-546.

25. Shi X., B rauburge r K., E 11 i o t t R.M. Role of N-linked glycans on bunyamwera virus glycoproteins in intracellular trafficking, protein folding, and virus infectivity. J. Virol., 2005, 79(21): 13725-13734 (doi: 10.1128/jvi.79.21.13725-13734.2005).

26. Gonzague M., Roger F., B a stos A., Burger C., Randriamparany T., $\mathrm{S}$ m o n d a c k S., C r u c i e r e C. Isolation of a non-haemadsorbing, non-cytopathic strain of African swine fever virus in Madagascar. Epidemiol. Infect., 2001, 126(3): 453-459 (doi: 10.1017/s0950268801005465).

27. B o in as F.S., Hutchings G.H., Dixon L.K., Wilki ns on P.J. Characterization of pathogenic and non-pathogenic African swine fever virus isolates from Ornithodoros erraticus inhabiting pig premises in Portugal. J. Gen. Virol., 2004, 85: 2177-2187 (doi: 10.1099/vir.0.80058-0).

28. O u ra C.A.L., D e n y e r M.S., T a $\mathrm{k}$ a $\mathrm{m}$ a t $\mathrm{s} u$ H., $\mathrm{P}$ a rk ho u s e R.M.E. In vivo depletion of CD8+ T lymphocytes abrogates protective immunity to African swine fever virus. J. Gen. $\mathrm{Vi}$ rol., 2005, 86(9): 2445-2450 (doi: 10.1099/vir.0.81038-0).

29. Souto R., Mutowembwa P., van Heerden J., Fosgate G.T., Heath L., Vos 1 o o W. Vaccine potential of two previously uncharacterized African swine fever virus isolates from Southern Africa and heterologous cross protection of an avirulent European isolate. Transbound. Emerg. Dis., 2016, 63: 224-231 (doi: 10.1111/tbed.12250).

30. K o lb a s o v D.V., S e r e d a A.D. Veterinariya, 2013, 1: 19-23 (in Russ.).

31. Jori F., B astos A.D.S. Role of wild suids in the epidemiology of African swine fever. EcoHealth, 2009, 6(2): 296-310 (doi: 10.1007/s10393-009-0248-7).

32. Roger F., Cruciи re C., Randriamahefa N., Zeller H., Uilenberg G., Randriamparany T., Gonzague M., Rousset D., Benkirane A., Diallo A. African swine fever in Madagascar: epidemiological assessment of the recent epizootic. Proc. $9^{\text {th }}$ Int. Symp. on Veterinary Epidemiology and Economics. Breckenridge, Colorado, USA, 2000.

33. Sereda A.D., Balyshev V.M., Morgunov Yu.P., Kolbasov D.V. Sel'skokhozyaistvennaya biologiya [Agricultural Biology], 2014, 1: 64-69 (doi: 10.15389/agrobiology.2014.4.64rus) (in Russ.).

34. B adaev F.A., Rudobel's ki i E.V., Chevelev S.F., K is e lev A.V., N ik is h in I.V., B ad a eva N.V., B u rlakov V.A., B a labanov V.A., Z a k ha rov V.M., B a ib i k ov T.Z., B u rdov A.N. Materialy nauchnoi konferentsii VNIIVViM «Voprosy veterinarnoi virusologii, mikrobiologii $i$ epizootologii» [Proc. Conf. «Veterinary virology, microbiology and epizootology»]. Pokrov, 1992, 1: 24-27 (in Russ.).

35. Badaev F.A., Cheryatnikov L.L., Rudobel'ski i E.V., Chevelev S.F., K i s e $1 \mathrm{ev}$ A.V., B a d a e va N.V., Z a k ha rov V.M., B a ibi k ov T.Z. Materialy nauchnoi konferntsii VNIIVViM «Voprosy veterinarnoi virusologii, mikrobiologii i epizootologii» [Proc. Conf. «Veterinary virology, microbiology and epizootology»]. Pokrov, 1992, 1: 44 (in Russ.).

36. Rodríguez J.M., Moreno L.T., Alejo A., Lacasta A., Rodríguez F., Sala s M.L. Genome sequence of African swine fever virus BA71, the virulent parental strain of the nonpathogenic and tissue-culture adapted BA71V. PLOS ONE, 2015, 10(11): e0142889 (doi: 10.1371/journal.pone.0142889).

37. Portugal R., Coelho J., Hoper D., Little N.S., S mithson C., Upton C., Martins C., Leitro A., Ke il G.M. Related strains of African swine fever virus with different virulence: genome comparison and analysis. J. Gen. Virol., 2015, 96: 408-419 (doi: 10.1099/vir.0.070508-0).

38. Morgunov Yu.P., Malogolovkin A.S., Morgunov S.Yu., Burmakina G.S., Kushnir S.D., Yurkov S.G., Tsybanov S.Zh., Kolbasov D.V. Veterinariya, 2015, 10: 53-57 (in Russ.). 
39. Krug P.W., Holinka L.G., O'Donnell V., Reese B., Sanford B., Fernandez-Sainz I., Gladue D.P., Arzt J., Rodriguez L., Ris atti G.R., Borc a M.V. The progressive adaptation of a Georgian isolate of African swine fever virus to Vero cells leads to a gradual attenuation of virulence in swine corresponding to major modifications of the viral genome. J. Virol., 2015, 89(4): 2324-2332 (doi: 10.1128/JVI.03250-14).

40. N e s e r J.A., Pidlli ps T., Thomson G.R., Gai naru M.D., Coetze e T. African swine fever. I. Morphological changes and virus replication in blood platelets of pigs infected with virulent haemadsorbing and non-haemadsorbing isolates. Onderstepoort J. Vet., 1986, 53: 133-141.

41. Reis A.L., Parkhouse R.M., Penedos A.R., Martins C., Le itão A. Systematic analysis of longitudinal serological responses of pigs infected experimentally with African swine fever virus. J. Gen. Virol., 2007, 88(9): 2426-2434 (doi: 10.1099/vir.0.82857-0).

42. Takamatsu H.H., Denyer M.S., Lacasta A., Sti rling C.M.A., Argilaguet J.M., Netherton C.L., O ura C.A.L., Martins C., Rodríguez F. Cellular immunity in ASFV responses. Virus Res., 2013, 173(1): 110-121 (doi: 10.1016/j.virusres.2012.11.009).

43. B r e d i k h i n a T.T., K o lo s o v V.M., A rk hi p o va S.N. Tezisy nauchno-teoreticheskoi konferentsii VNIIVViM, posvyashchennoi 60-letiyu obrazovaniya SSSR [Proc. Conf. of ARRIVV\&M]. Pokrov, 1983: 120-123 (in Russ.).

44. B r edik hin a T.G., K olos ov V.M. Tezisy nauchno-teoreticheskoi konferentii VNIIVViM, posvyashchennoi 60-letiyu obrazovaniya SSSR [Proc. Conf. of ARRIVV\&M]. Pokrov, 1983: 123124 (in Russ.).

45. S e reda A.D. Nauchnyi zhurnal KubGAU, 2010, 62(8). Available http://ej.kubagro.ru/2010/08/pdf/23.pdf. No date (in Russ.).

46. Vigario I.D., Terrinha A.M., Moura $\mathrm{Nunes}$ J.F. Antigenic relationships among strains of African swine fever virus. Archiv fur die gesamte Virusforschung, 1974, 45(3): 272-277.

47. Borca M.V., Kut ish G.F., A fonso C.L., Irusta P., Carrillo C., Brun A., $\mathrm{S}$ us sman M., Rock D.L. An African swine fever virus gene with similarity to the Tlymphocyte surface-antigen Cd2 mediates hemadsorption. Virology, 1994, 199(2): 463-468 (doi: 10.1006/viro.1994.1146).

48. Rodríguez J.M., Yáce z R.J., Almazán F., Vicuela E., Rodriguez J.F. African swine fever virus encodes a $\mathrm{Cd} 2$ homolog responsible for the adhesion of erythrocytes to infected-cells. J. Virol., 1993, 67(9): 5312-5320.

49. Kay-J a cks o n P.C., Go at ley L.C., C ox L., M iskin J.E., Parkhouse R.M., W i e $n$ a nds J., D ix o $n$ L.K. The CD2v protein of African swine fever virus interacts with the actin-binding adaptor protein SH3P7. J. Gen. Virol., 2004, 85(1): 119-130 (doi: 10.1099/vir.0.19435-0).

50. M i ma K.A., B urmakina G.S., Titov I.A., Malogolovkin A.S. African swine fever virus glycoproteins $\mathrm{p} 54$ and $\mathrm{CD} 2 \mathrm{v}$ in the context of immune response modulation: bioinformatic analysis of genetic variability and heterogeneity. Agricultural Biology, 2015, 50(6): 785 793 (doi: 10.15389/agrobiology.2015.6.785eng) (in Engl.).

51. Ruiz-Gonzalvo F., Rodríguez F., Escribano J.M. Functional and immunological properties of the baculovirus-expressed hemagglutinin of African swine fever virus. Virology, 1996, 218(1): 285-289 (doi: 10.1006/viro.1996.0193).

52. Go at ley L.C., Dix o n L.K. Processing and localization of the African swine fever virus CD2v transmembrane Protein. J. Virol., 2011, 85(7): 3294-3305 (doi: 10.1128/JVI.01994-10).

53. Tulma n E.R., D e 1 h o n G.A., Ku B.K., R o ck D.L. African swine fever virus. Curr. Top. Microbiol. Immunol., 2009, 328: 43-87.

54. Dixon L.K., Abrams C.C., B owick G., Goatley L.C., Kay-Jackson P.C., Chapman D., Liverani E., Nix R., Silk R., Zhang F. African swine fever virus proteins involved in evading host defense systems. Vet. Immunol. Immunopathol., 2004, 100(3-4): 117-134 (doi: 10.1016/j.vetimm.2004.04.002).

55. Galindo I., Almazán F., Bustos M.J., Vicuela E., Carrascosa A.L. African swine fever virus EP153R open reading frame encodes a glycoprotein involved in the hemadsorption of infected cells. Virology, 2000, 266(2): 340-351 (doi: 10.1006/viro.1999.0080).

56. Burmakina G., Malogolovkin A., Tulman E.R., Zsak L., Delhon G., Di e 1 D.G., Shobogorov N.M., Morgunov Y.P., Morgunov S.Y., Kutish G.F., Kolbasov D., Rock D.L. African swine fever virus serotype-specific proteins are significant protective antigens for African swine fever. J. Gen. Virol., 2016, 97(7): 1670-1675 (doi: 10.1099/jgv.0.000490).

57. Neila n J.G., B orca M.V., Lu Z., Kutish G.F., Kle iboeker S.B., Carrillo C., Z s a k L., Rock D.L. An African swine fever virus ORF with similarity to C-type lectins is non-essential for growth in swine macrophages in vitro and for virus virulence in domestic swine. J. Gen. Virol., 1999, 80(10): 2693-2697 (doi: 10.1099/0022-1317-80-10-2693).

58. Hurtado C., Granja A.G., Bustos M.J., Nogal M.L., Buitrago G.G., Yébenes V.G., S a las M.L., Revilla Y., Carrascosa A.L. The C-type lectin homo- 
logue gene $(E P 153 R)$ of African swine fever virus inhibits apoptosis both in virus infection and in heterologous expression. Virology, 2004, 326(1): 160-170 (doi: 10.1016/j.virol.2004.05.019).

59. Hurtado C., Bustos M.J., Granja A.G., Leyn P., Sabina P., Lypez-Viñas E., Gy mez-Puertas P., Revilla Y., Carrascos a A.L. The African swine fever virus lectin EP153R modulates the surface membrane expression of MHC class I antigens. Arch. Virol., 2011, 156: 219-234 (doi: 10.1007/s00705-010-0846-2).

60. Chapman D.A., T cherepanov V., Upton C., Dixon L.K. Comparison of the genome sequences of nonpathogenic and pathogenic African swine fever virus isolates. J. Gen. Virol., 2008, 89: 397-408 (doi: 10.1099/vir.0.83343-0).

61. Leitro A., Cartaxeiro C., Coelho R., Cruz B., Parkhouse R.M., Portuga 1 F., Vigario J.D., M a rtins C.L. The non-haemadsorbing African swine fever virus isolate ASFV/NH/P68 provides a model for defining the protective anti-virus immune response. $J$. Gen. Virol., 2001, 82(3): 513-523 (doi: 10.1099/0022-1317-82-3-513).

62. Malogolovkin A., Burmakina G., Tulman E.R., Delhon G., Diel D.G, Salnikov N., Kutish G.F., Kolbasov D., Rock D.L. African swine fever virus CD2v and C-type lectin gene loci mediate serological specificity. J. Gen. Virol., 2015, 96: 866873 (doi: 10.1099/jgv.0.000024).

63. Rowlands R.J., Duarte M.M., Boinas F., Hutchings G., Dixon L.K. The $\mathrm{CD} 2 \mathrm{v}$ protein enhances African swine fever virus replication in the tick vector, Ornithodoros erraticus. Virology, 2009, 393(2): 319-328 (doi: 10.1016/j.virol.2009.07.040).

64. Sereda A.D., Anokhina E.G., Fugina L.G., Makarov V.V. Veterinariya, 1993, 1: 26-28 (in Russ.). 